\title{
Student Opportunity: Short-Term Exposure to International Agriculture
}

\author{
Ronald L. Phillips • Noel P. Magor • David Shires • \\ Hei Leung • Susan R. McCouch $\cdot$ Duncan Macintosh
}

Received: 2 June 2008 / Accepted: 3 June 2008 / Published online: 15 August 2008

(C) Springer Science + Business Media, LLC 2008

\begin{abstract}
Opportunities abound to apply crop science to solving many of the world's food problems. International agricultural research centers (IARCs) provide a window through which students can see the need for improved agricultural productivity and briefly experience the rewards of working on difficult but important issues. In today's world of highly technical graduate education, students find it difficult to obtain exposure to international agriculture due to the extreme constraints on their time. Programs for students that provide a short-term exposure to IARC strategies can have long-term benefits for the student as well as the international center. A short-term student exchange program between a US university and the International Rice Research Institute (IRRI) and a special course on rice (research to production) offered at IRRI provide students with unique insights for averting food riots in the future. Details of these educational efforts are described in this paper.
\end{abstract}

\footnotetext{
R. L. Phillips $(\bowtie)$

Department of Agronomy and Plant Genetics,

University of Minnesota,

St. Paul, MN, USA

e-mail: phill005@umn.edu

\section{N. P. Magor · D. Shires}

Training Center, International Rice Research Institute,

Los Baños,

Laguna, Philippines

N. P. Magor

e-mail: n.magor@cgiar.org

D. Shires

e-mail: d.shires@cgiar.org
}

Keywords International agriculture - World Food Crisis . Graduate student education - Consultative Group on International Agricultural Research (CGIAR) . International Rice Research Institute (IRRI) . University of Minnesota/IRRI Shuttle Internship Program . "Rice: Research to Production". International Agricultural Research Centers (IARCs)

\section{Introduction}

The world food crisis is prominent in today's news. The sustainable production of food and household food security are high on the agenda globally. World food reserves are low, and the spike in food prices is alarming. The Millennium Development Goals will need to be revised, as many households again sink back into poverty and as many, and more, remain mired there.

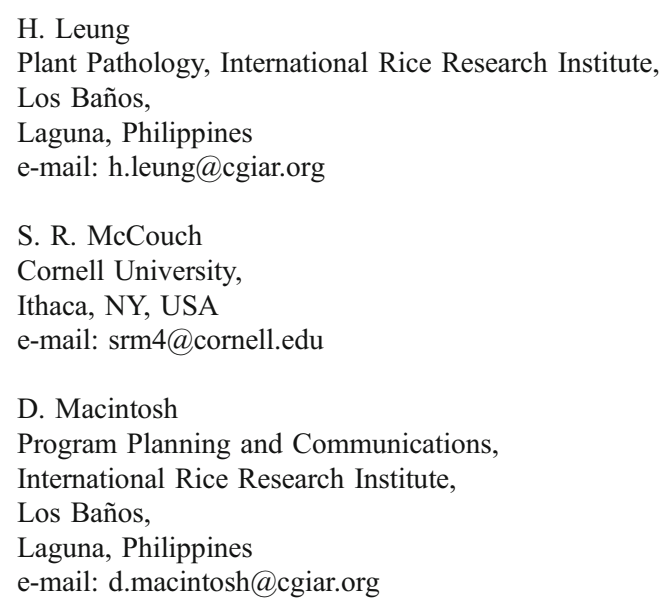


Students' experiences in other countries change their lives forever. We have seen that this is especially true for students participating in research in the developing world. Exposure to the basic unmet needs of people around the world puts in perspective the value of research and teaching in agriculture. Many of today's issues, such as the doubling of the price of basic staples, the dwindling stockpiles of food grain, and the number of people with essentially no income (162 million people live on less than US \$0.50 per day [6]) highlight the need for urgent action on behalf of the world's most deprived peoples and clearly have an impact on all of us. From the perspective of a university student, the professional path to a career in international agricultural research and development may not be obvious. Many students aspire to be part of the solution but have no idea how to contribute or where they might fit in.

We are aware of many factors contributing to the current food crisis. For rice, there has been the unseasonable weather with extensive flooding and a severe cyclone in Bangladesh, prolonged drought in Australia, and the current tragedies in Myanmar and China. Coupled with these has been a brown planthopper pest and associated disease outbreak in Vietnam. The news media have also highlighted the neglect in funding for agricultural research [1]. In addition, we have become acutely aware of climate change and the impact that this may have on food production systems.

International agricultural research centers (IARCs) such as the Future Harvest Centers of the Consultative Group on International Agricultural Research (CGIAR) are places where the application of science is clearly a powerful way to make a difference in this world. In this paper, we would like to highlight the International Rice Research Institute (IRRI). IRRI was founded in the Philippines in 1960 as a center for rice research and education to meet the threat of famine in the Asian region. IRRI's program embraced both technical and policy research aimed at developing strategies for reducing the risk of famine and building food security. The second and equally important role that IRRI took on was in building a generation of scientists in the region. This thrust through the 1960s and 1970s gave rise to the Green Revolution in rice (and similarly in wheat at IRRI's sister institute, Centro Internacional de Mejoramiento de Maíz y Trigo). IRRI has continued its research and education in and out of season, with abundant or scarce resources. Even in the recent climate of fewer resources, IRRI has recognized the need to develop the next generation of rice scientists to meet the long-term challenges to rice food security. A global network of scientists, along with alliances for impact, must underpin the rice systems of the future.
It is strikingly clear that even short-term exposure to the IRRI research agenda provides students with the intrinsic feeling that they are doing something important. The serious, positive philosophy that students detect at such centers will likely have a major impact on their future careers. The 15 CGIAR centers (http://www.cgiar.org/) sponsor research in more than 100 countries. These centers have an educational obligation in addition to research, so the opportunities for students are overwhelming. In addition to the CGIAR centers, there are many other IARCs contributing to these goals.

The traditional approach to providing international agriculture exposure to students is to do a thesis or part of a thesis at an international center (in so-called "sandwich programs"). The primary challenge is that international thesis research requires a commitment of several years overseas and this may not fit the agenda of the great majority of students. Thus, most students do not acquire any exposure to the needs and opportunities for international agricultural research. Today's students place great value on receiving a cutting-edge education using the latest technology and instrumentation. They are well aware of the level of competitiveness required to be successful in their fields. The average age at which a new independent investigator receives his or her first grant is 42 [4]. Students are keenly tuned to the need to be well informed and well trained in a variety of sophisticated research strategies and technologies, and most students do not see a way to integrate technical training with international agricultural research. Consequently, they graduate with little or no understanding of the international research infrastructure and how it achieves useful results in the developing world. Furthermore, reductions in core funds within the CGIAR [2] have seriously eroded the capacity to launch new training initiatives in recent years.

The World Food Prize Youth Institute, developed by Nobel laureate Norman Borlaug, provides bright high school students with the opportunity to experience 2-month terms of in situ exposure to research at an international agricultural research center. This opportunity opens a whole new world to them. Many US university faculties also have had short-term experiences in various countries and return better informed and more deeply committed to providing similar opportunities for their students. The challenge is to bring together people with diverse intellectual backgrounds and focus their energy into a common scientific tour de force to address global problems in agriculture. Per Pinstrup-Andersen, former chair of the CGIAR Science Council, recently identified a worthy challenge. He noted, "The global food system is in disarray... and the focus of science for the global food system should be on creating more with less, assuring sustainability in the management 
of natural resources and utilizing all appropriate scientific methods" (2008) [5].

The question raised by the current scenario is how can we encourage students interested in the latest scientific methods to consider a career in international agricultural research? We believe that short-term exposure at an IARC can provide students with insights that will make them more likely to apply for positions at IARCs. We would like to highlight two programs that are designed to help orient students in their professional journey, especially as they seek ways to become engaged in responding to the rice crisis, and become involved in finding solutions.

\section{University of Minnesota/IRRI shuttle internship program}

The University of Minnesota signed a memorandum of understanding with IRRI to have several graduate students in the Applied Plant Sciences Program spend 6 weeks to 3 months at IRRI. In the 2007-2008 academic year, five students took advantage of the opportunity. The positive experiences of every one of these students prompted the idea of sharing information on the University of Minnesota/ IRRI Shuttle Internship Program in this first issue of the journal, RICE. This experience can be transferred across universities and various IARCs.

The University of Minnesota/IRRI Shuttle Internship Program includes the following steps:

1. The University of Minnesota Applied Plant Sciences Director of Graduate Studies notifies qualified students of the opportunity.

2. Students express an interest in participation to the chair of the University of Minnesota/IRRI program.

3. The program chair gives IRRI's Strategic Plan to the interested students.

4. If a student wishes to participate, she/he obtains the advisor's consent and identifies a possible time period.

5. The student reviews IRRI's previously provided list of five to ten areas of interest and respective mentoring personnel.

6. The training officer at IRRI receives information on the student's primary interest.

7. The training officer arranges for a mentor among the IRRI faculty.

8. The deputy director general for research confirms the internationally recruited staff host to the chair of the University of Minnesota/IRRI program, and then, the IRRI mentor and student, in concert with the advisor, develop a final plan for the internship.
9. The IRRI Training Center issues an invitation letter for visa purposes that confirms the student's commitment to participate in the research internship.

10. The student meets with the University of Minnesota Director of International Programs in Food, Agricultural and Natural Resource Sciences (IPFANS) to review the memorandum of understanding conditions relative to such matters as intellectual property and university procedures regarding international health insurance, liability waivers, medical history, emergency contact information, visas, airline tickets, and final internship plan.

11. The student may consider registering in an appropriate University of Minnesota course for credit.

12. IPFANS purchases the airline ticket.

13. The student spends 6 weeks to 3 months at IRRI; travel is paid by the University of Minnesota; expenses for housing, meals, and research are paid by IRRI.

14. IRRI assumes responsibility for receiving the student upon her/his arrival, provides orientation, arranges the departure from IRRI, and communicates with the University of Minnesota director of IPFANS.

15. The student provides oral reports at IRRI and at the University of Minnesota.

Students in the University of Minnesota/IRRI Shuttle Internship Program have participated in many scientific studies. These have included insect transmission tests using enzyme-linked immunosorbent assay, mapping of disease resistance genes, testing for the involvement of candidate genes, various greenhouse screening tests, designing polymerase chain reaction (PCR) and real time-PCR primers, and optimizing the amplification process, bioinformatics tests, flood tolerance, anaerobic germination, marker-assisted backcrossing, targeted-induced local lesions in genomes, selection of mutants, and pyramiding of genes. The students may also gain interesting experiences outside of the IRRI campus (Figs. 1 and 2).

Some comments of the participating students follow:

Alex Rigor, a graduate student in the Applied Plant Sciences (APS) graduate program, was the first student to participate in the University of Minnesota/IRRI Shuttle Internship Program. He concluded: "(1) Overall, the internship was a great experience; (2) IRRI scientists and staff are very accommodating; (3) Excellent coordination with other research programs."

Robenzon Lorenza, the second APS student to participate, said that the experience: "(1) led to increased awareness of agricultural problems relevant on an international scale; (2) resulted in a greater 


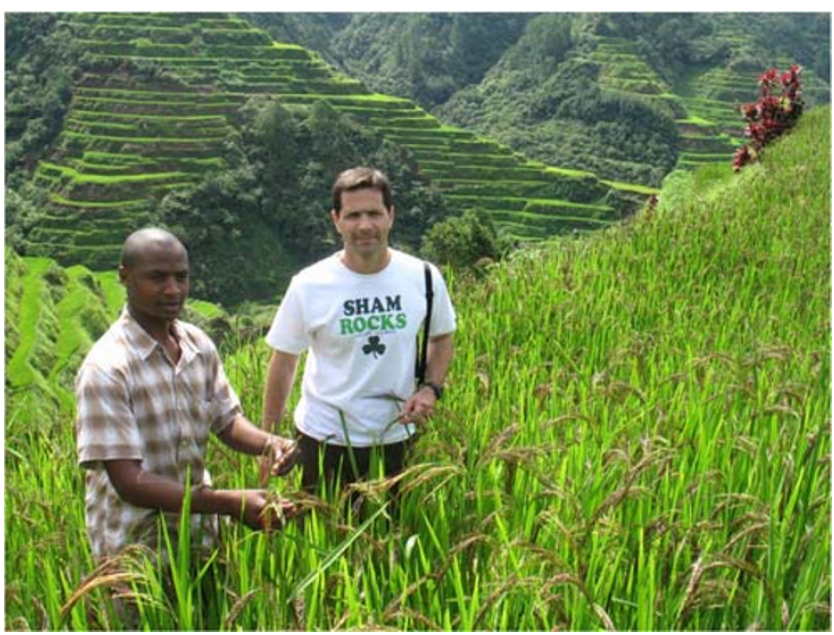

Fig. 1 Students learning about rice culture at the Banaue rice terraces in the Philippines.

interest in pursuing a career at an international research center."

Patricio Mayor, an APS graduate student from Argentina, added: “(1) IRRI researchers are very accessible; (2) excellent opportunity to experience another culture."

\section{"Rice: research to production" 3-week course-a new generation, a new revolution}

This exciting program was launched at IRRI in 2007 to encourage some of the world's best and brightest young scientists to consider careers helping developing nations. It started in response to growing concerns that young scientists doing advanced biological research in the advanced laboratories in the West are increasingly unaware of how their work could have a major impact on the problems faced by many poorer nations. Recent scientific breakthroughs, such as the sequencing of the rice genome [3], have triggered exciting new translational research into ways to help poor farmers overcome such age-old problems as drought, flooding, and high levels of salinity.

It was felt that many young scientists working in developed nations are increasingly isolated from the very people in poorer nations who could really benefit from their work. We want to change this and encourage good young scientists, wherever they are, to take the latest scientific knowledge and use it in creative new ways to improve the lives of the world's poor.

This course has been sponsored by the National Science Foundation (NSF) in the USA, the UK's Gatsby Foundation, and IRRI. In its first year, it attracted 26 participants from 12 nations, with half coming from the USA and

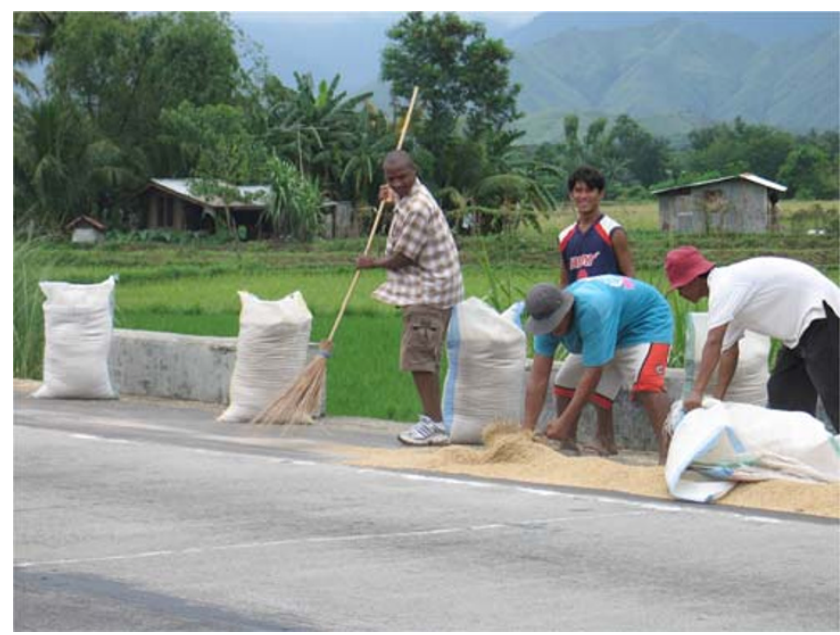

Fig. 2 A student helping to collect rice that had been dried beside the road near IRRI.

European Union and half coming from rice-growing countries in Asia and Africa. It is now in its second year, with 28 participants. During the course, participants learn first the basics of rice such as how it is sown, cultivated, and harvested. They learn about rice research activities in the labs and receive hands-on experience in the field in areas such as rice breeding, crop management, and postharvest.

"Considering the ongoing revolutions in fields such as molecular biology and bioinformatics, this is an incredibly exciting time to work in agricultural research because we are finally gaining the knowledge we need to solve some of the developing world's most intractable and difficult problems," IRRI's director general, Robert S. Zeigler, said. "What we have to do now is make sure the young scientists of the world are aware of the unprecedented-almost historic - opportunity they have to really make a difference in the lives of the poor."

This course provides a prime opportunity for young scientists and development professionals to "get their feet wet" and to recognize that they could be part of the solution to the current world food crisis. For the organizers from Cornell University and IRRI and for IRRI as a whole, it was an exceptionally positive experience to share in the energy of the talented next generation of scientists.

Comments from first-year participants:

"The course made me better appreciate the importance of applied agriculture," said one of the participants, Megan O'Rourke, who was sponsored by the NSF. Megan is a 27-year-old mother of three doing her $\mathrm{Ph}$. D. in ecology and evolutionary biology at Cornell University in the USA. Megan said it was the first time she had visited a developing nation and been able to see the economic conditions first-hand. "It has reminded me that I began studying agriculture because of its essential place in supporting lives and societies." 
Zoe Rutterford, a 23-year-old first-year Ph.D. student at Cambridge University, sponsored by the UK's National Institute for Agricultural Botany and the Gatsby Foundation, is studying how different aspects of gene structure and function contribute to the success of barley varieties. "I feel that this course has restored my interest in pursuing a career in development and agricultural research," she said.

An added unique dimension to the course is that it brings together budding scientists and development professionals from both developed and developing countries. The experience of working on a joint project that is crossdisciplinary, covers a range of countries, and involves both men and women learning together over 3 weeks gives the course an international flavor and gives the participants an appreciation of being part of a global community. Zoe commented, "It has been inspiring to join a group of scientific contemporaries and senior professionals, whodespite originating from a hugely diverse range of backgrounds - have so much in common."

\section{Conclusions}

Programs such as the two described above (1) expose undergraduate and graduate students of both developed and developing-country universities to the important roles of an IARC in international agriculture, (2) increase student awareness of the food staples in the developing world and of concerns about producing them in an environmentally sustainable manner, (3) encourage students to consider a career at an IARC or other international organization, (4) offer an assessment of the philosophies of international scientists and the issues of applying new practices on an international scale, (5) provide an opportunity for the student to learn about the history of the IARC and the role it has played over the years in alleviating hunger and poverty in many countries beyond where the center is currently located, (6) document the extent of the scientific facilities and capabilities of an IARC, (7) provide information on available germplasm and various breeding methods, (8) provide an opportunity to experience the culture of the host country, and (9) lead to enhanced collaboration between universities and IARCs. Programs of this sort can help to internationalize science education programs and mobilize a large cadre of young scientists to contribute in diverse ways to the process of increasing the sustainability and productivity of agriculture throughout the developing world.

\section{References}

1. Bradsher K, Martin A. The food chain -World's poor pay price as crop research is cut. http://www.nytimes.com/2008/05/18/business/ worldbusiness $/ 18$ focus.html?hp $\% 3 \mathrm{Cbr} \% 3 \mathrm{E}=$ \&pagewanted $=$ all. 2008.

2. CGIAR Science Council. Evaluation and impact of training in the CGIAR. Science Council Secretariat, 2006, p. 97.

3. International Rice Genome Sequencing Project. The map-based sequence of the rice genome. Nature 2005;436:793-800.

4. Kaiser J. Panel weighs starter R01 grants. Science 2004;304:1891.

5. Pinstrup-Andersen, Per. Science and policy priorities for the global food system. Executive Summary of topical lecture presented at the 2008 AAAS Annual Meeting. Boston, MA, 2008.

6. von Braun, J. Urgent action needed for worlds most deprived. IFPRI Forum. 2007 October/November. 